the least losing all value as a hæmostatic barrjer; or it may, if large, act as a direct irritant, and induce both inflammation and suppuration within the sac.

The second condition demands that the blood should possess a given constitution; and this, if originaliy defective (so far as we at present know), either chemically or clinically, can be but very imperfectly corrected. This aplastic quality of the blood, if we investigate the cause of death in many cases, will be found to have been, apparently, the sole impediment to cure.

The third requirement consists in a certain physical peculiarity and arrangement, so far as relates to the state of the orifice of the sac and the condition of its inner walls. If the mouth of the sac be wide, as in the crateriform aneurism, and the walls comparatively smooth, the formation of coagulum is nuch impeded; but if the neck be narrow, and the walls roughened by calcareous or atheromatous deposit, it constitutes a veritable straining chamber; and then, the other conditions being present, the plasmine divides, allowing fibrin to settle, molecule by molecule, with that singular mode of adhesion and formation of laminæ-the most internal hyaline, the external still fibrillary-so well investigated and described by Robin in his "Lectures on the Normal and Morbid Fluids of the Body" (p. 161).

(To be concluded.)

\section{AN EXPLANATION}

$$
\text { OF }
$$

\section{THE CAUSE OF SCURVY AND THE ACTION OF THE DIFFERENT SO-CALLED} ANTISCORBUTICS ;

\section{WITH SUGGESTIONS AS TO THE BEST MEANS OF PREVENTING THE DISORDER.}

Bx ARCHER FARR, L.R.C.P. EDIN., \&c.

THere have been many speculations with regard to the cause of scurvy: one authority affirming that it is owing to the absence of vegetables in the food taken; another maintaining that a deficiency of the salts of potash is the cause; while a third gives it as his opinion that it results from bad ventilation, deficient water-supply, wet seats, \&c.,-all of which fail to explain the real cause of the disease. That scurvy is not owing to a deficiency of the salts of potash in the food of the sailor, and that salt meat contains all the elements necessary for nutrition, have been proved beyond doubt; while that the belief that fresh succulent vegetables or lime-juice are indispensably necessary to the cure of the disorder is an error, is proved by the fact that beef-tea and milk will effect a cure in the absence of both. If salt meat contains all the elements required for nutrition, how does it produce scurvy? Purely by its hard and indigestible nature as food, and its inability, from its resistance to peptic change, to supply for any length of time all the conditions necessary for proper digestion. Added to this is man's natural aversion to the continued use of one, and only one, kind of food for any length of time.

Physiology teaches us that the gastric fluid is secreted only in the presence of food; but that it ceases to be secreted, although food be present in the stomach, as soon as the wants of the system are satisfied. Now, what takes place during digestion where the only food employed consists of salt meat-sometimes of the consistence of buckhorn-and dry biscuit? The food remains in the stomach probably five or six hours, while the wants of the system continue unsatisfied. All this time the stomach is being excited to secretion, while the gastric juice, from this exhausting secretory action, becomes deteriorated in quality, or in the end, perhaps, deficient in quantity; and the result is that the whole digestive process is brought to a standstill. Scurvy, therefore, is the result of mal-nutrition. But we know that if lime-juice or vegetables be added to the staple fare of salt meat and biscuit, scurvy may be pre- vented. And the prophylactic power of the lime-juice does not, as is generally supposed, depend upon its having any direct action upon the blood, but upon its immediate action on the contents of the stomach, by serving as the agent by which these hard ingesta become reduced and rendered fit for absorption-in fact, by taking the place of the gastric fluid. Now, what facts have we to strengthen this hypothesis? In the first place, that the solvent power of the gastric fluid depends, for the most part, upon the acid it contains, it having been found to yield, on analysis, hydrochloric, acetic, lactic, malic, and phosphoric acids; one being capable of taking the place of the other. Hence it is that the acid wines and vinegar become antiscorbutics. Secondly, that the solvent effect of the different acids upon the fibrin of meat is well known, and is taken advantage of in making analyses of the contents of the different viscera in medico-legal investigations. We learn by experience that saur-kraut, spruce-beer, oranges, lemons, and their juices, and all kinds of esculent fruits and vegetables, possess more or less so-called antiscorbutic properties; also, that the acid wines, vinegar, brandy, molasses, pickles, and sauces tend greatly to prevent the occurrence of scurvyindeed, it would be difficult to name anything contained in the category of eatables and drinkables which does not possess, to a greater or less degree, some antiscorbutic value. Now, it must be patent to all who possess the smallest knowledge of chemistry, that if vinegar and brandy serve at all to prevent the disease, it cannot be owing to the salts of potash they contain; while it is equally certain that ther must operate in a manner quite different from that in which potatoes and green vegetables effect a cure. The juice of the lime and lemon, acid wines, beer and vinegar, act by virtue of their solvent effect upon the food contained in the stomach; whereas alcohol can only act through the medium of the circulatory system. The secret of vegetables and fruits being so potent as antiscorbutics is this:-The alimentary canal may be very appropriately termed a double organ, inasmuch as the animal food is digested by the stomach, and the vegetables by the intestines. Hence man has two distinct appetites, one for each kind of food-the animal and vegetable. He may eat to repletion of the one kind, and then partake heartily of the other. Is it not fair to assume, then, that, in the case of the scorbutic patient whose stomach digestion has been most imperfect, the intestines, which for weeks have been almost wholly unem. ployed, should, upon the accession of vegetable food, play an active part in supplying the necessary nutritive material to the system? Scurvy is to be prevented, then, in two ways: either by employing the stomach better, or by giving the intestines more to do.

Food should be so constituted as to contain within it the materials from which may be drawn all the primary elements of the blood; and no one liind of food is so rich in these as flesh, the fibrinous portions being the most essential. It is true that wherever scurvy has happened, whether on land or sea, it has always been in the absence of vegetable food; but what other condition is there that strikes one? That the fibrinous and albuminous portions have always been deficient in the materia alimentaria supplied, or they have been presented in such a form as not to admit of their being, for any length of time, properly and effectually reduced; the latter being the case where salt meat has been the cause, and the former where bread, tea, coffee, bacon, cheese, \&c., have formed the diet under which an outbreak of scurvy has talren place. We have sufficient proof that the fibrinous and albuminous principles play a most important part in eradicating scurvy in the fact that vegetables will sooner effect a cure when combined with salt meat than when administered alone, and still quicker conduce to such result when taken in conjunction with fresh meat. And again, a healthy, growing youth, with craving appetite, whose stomach is equal to any emergency in the way of food, will outlive a much longer voyage on salt meat and biscuit than the man in middle life with fastidious stomach; although in the case of the youth the demands of the system for food are greater, in order to supply the wants of a growing frame. What stronger arguments can be adduced in favour of my theory? What greater proof can we have, in opposition to the prevailing opinion, that vegetables are chemically antiscorbutic-that they supply a something which meat does not possess, and which the body requires? The four varieties of food necessary for the main- 
tenance of nutrition are represented in bread and butter, and how commonly do we see well-nourished, blooming children living almost exclusively upon it. But the fibrinous and albuminous principles contained therein being proportionately very small, it would fail to supply the necessary muscle-making material were it not for the child's astonishing capacity for consuming its own weight of such food in a comparatively short time. The adult in attempting to live exclusively upon bread and butter would find that he could not eat sufficient to sustain him. And hence it is that children will thrive under the same conditions that infallibly conduce to scurvy in the adult. It is remarkable that the many different authors writing upon this subject should not have observed this.

The great desideratum, then, in catering for the mercantile marine, with a view to prevent the occurrence of scurvy, should be that the sailor be provided with good fleshfood; and since salt meat must of necessity always form the basis of his dietary, every care should be taken that it be of recent pickle, bad salt meat being too commonly the cause of the disorder. Nothing would tend more to stamp out scurvy from our seas than Government making it compulsory on ship-owners not to ship their meat-supply as salt meat, but compel them to take it in as fresh meat, and thus ensure its being laid down in the brine within a week of the vessel's sailing. This plan could not fail to secure to the sailor a supply of wholesome meat, whereas, as the law stands, he may have palmed upon him the vilest trash, the pickle-tub being made the receptacle of all that is loathsome. The carcase once in the brine, there is an end to all history as to its mode of death; neither do we know how long it may have been "sepulchred below ;" and consequently many a ship is sent to sea with scurvy in the tub.

(To be continued.)

ON

\section{THE ADMINISTRATION OF FOOD AND MEDICINE BY THE NOSE WHEN THEY CANNOT BE GIVEN BY THE MOUTH.}

BY D. ANDERSON MOXEY, M.D., M.R.C.P.

(Concluded from p. 395.)

IN the manner before mentioned, I have administered every kind of liquid and semi-solid food, as milk, beef-tea, soups, eggs, arrowroot, corn-flour, Liebig's extractum carnis, \&c.; and every kind of drink, as tea, coffee, barley-and rice-water, wine, and spirits diluted with water. I have also given in the same way every kind of drug; and, out of an experience of some scores of cases, $I$ have never found the nostrils unduly irritated during the administration, so as to induce sneezing or paroxysmal coughing, as might at first sight be expected; nor have I ever heard the patient subsequently complain of any injury to, or even irritation of, the nostrils; nor have I ever found the trace of a scratch or contusion on the person of a patient fed in this way. Moreover, $I$ have never known the lunatic express any violent resentment at the treatment pursued, nor aver that he had been injured in any way during the administration; and I have invariably found those who assisted at, or witnessed, the procedure express their unqualified approbation of the system. It is surprising to those who have not experience of it, to what an amount of apparent irritation the nares may be subjected without giving rise to discomfort, and what a large quantity of fluid or semi-solid nourishment may be administered by the nose in the space of a few minutes. In order thoroughly to test these points, I instituted a series of experiments on myself, administering through my own nostrils warm and cold water, diluted brandy, eggs beaten up in milk, \&c. In no instance was there produced irritation enough to cause my eyes to water. The sensation could neither be called painful nor irritable, but it was sufficiently unpleasant to make me understand and appre- ciate the reason why many patients, after a very short trial, prefer to take their food in the usual way. The peculiar feeling lasts but a few minutes after the administration, and is similar in kind to, and certainly not greater in degree than, the sensation of discomfort that follows diving, when the sea-water is forced into the mouth or throat through the nostrils. I found I could with ease swallow in this manner a pint of the mistura vini gallici of the British Pharmacopœia, with the addition of a teaspoonful of Liebig's extractum carnis; and this potion caused less discomfort to the Schneiderian membrane than a similar quantity of cold water. This was due to my having previously warmed the brandy mixture, which further enabled me to swallow the whole pint in three minutes, whereas the cold water was nearly five minutes in being disposed of. These few experiments taught me that the Schneiderian membrane is by no means so sensitive as we are apt to imagine, but that it is more sensitive to cold than even to stimulating liquids. Hence I have deduced, and would recommend to others, the practical rule always to warm whatever is administered through the nose.

It may be asked, why do patients, as a rule, give in so much more readily than when food is forced on them through the mouth? There are various reasons for this, I believe. In the first place, most patients, however insane they may be, have a tolerably shrewd appreciation of the power of numbers, and seeing an overwhelming force arrayed against them in the four or five attendants $I$ have recommended to be summoned on these occasions, and not exactly knowing what is going to be done, a feeling of alarm often prompts them to give in, even before they are laid down on the couch. The appearance of the physician with the funnel and sauceboat still further magnifies in their eyes the extent and apparent mysteriousness of the preparations. In the second place, when they are held down on the couch so that every movement is absolutely controlled, the feeling that they are utterly powerless, and that resistance is simply impossible, doubtless often conquers their obstinacy, and leads them to make a virtue of a necessity. At the same time, this feeling of utter helplessness is not agreeable to the natural vanity of anyone, sane or insane; the patient feels as if he were being degraded and treated like a child, and in some instances this idea seems to prompt the unconditional surrender. Sooner than again be placed in so humiliating a position, I have seen several patients, who had previously fought desperately against all attempts to feed by the mouth, take their food quietly and in the usual way, after once having had their vanity so wounded. In the third place, when the funnel and sauce-boat have been called into requisition, the sensation, as already stated, is quite disagreeable enough to bring most patients to terms, particularly when the luxury of a stout resistance is so completely precluded.

On the other hand, when food is forced by the mouth, not only are the voluntary muscles of the whole body arrayed against the attempt, but the muscles of the mouth itself, even if the others are thoroughly controlled, can be used as antagonistic agents to the last; and it is wonderful how the patient enjoys to bespatter the attendants with the halfswallowed food. He never feels, as in the other case, wholly in the power of those around him; and, so long as the veriest loophole for resistance is open, he fights to the last, and is ready to fight again. The more he is hurt the more savage he becomes; and he will sometimes even glory in his bruises and abrasions, if he can only trace some of his own handiwork on the clothes or persons of those who forced the food down his throat.

In narrating my experience of this method of administerin food, I have explained, in the first instance, its exhibition to the insane. In the advocacy of a procedure as yet untried by the greater part of the profession, it is, perhaps, unwise of me to have first referred to such cases, surrounded, as they always are, by so many repulsive adjuncts; for it is painful to be compelled to use force of any kind to a fellow-creature, and especially to a fellow-creature suffering under so sad an affliction as insanity-in fact, it is pain. ful even to write about it. But it was in the Hants County Lunatic Asylum, of which I was assistant medical officer ten years ago, that $I$ first saw the plan adopted; and it was in consequence of the good results I derived from its use there, that I was induced subsequently to try it in various diseases and states of the system unconnected with insanity. 